\title{
PRODUÇÃO HABITACIONAL NA REgIÃo METROPOLITANA DE FORTALEZA NA DÉCADA DE 2000:
}

AVANÇOS E RETROCESSOS

\author{
Clarissa Sampaio Freitas \\ Luis Renato Bezerra Pequeno \\ Universidade Federal do Ceará, Departamento de Arquitetura e Urbanismo, Fortaleza, CE, Brasil
}

\begin{abstract}
R E S U M O : O crescimento da informalidade urbana brasileira tem sido entendido como subproduto da pouca atuação do Estado na política habitacional, aliada a um mercado imobiliário concentrado nas camadas de alta renda. Entretanto, a partir de meados da década 2000, aumenta-se significativamente o volume de recursos federais para a provisão habitacional de baixa renda, gerando novos mercados habitacionais. Para contribuir com as análises sobre os efeitos socioespaciais desta mudança, este artigo questiona em que medida ela favoreceu o acesso ao espaço urbanizado pela população de baixa renda na Regiāo Metropolitana de Fortaleza. Utilizando-se de sistema de informaçôes geográficas, entrevistas semiestruturadas e dados secundários, identifica-se um descolamento entre os investimentos em habitação e as diretrizes de inclusão contidas na politica urbana local. Se, por um lado, amplia-se a produção formal para as rendas inferiores, por outro lado, o não enfrentamento da questão fundiária póe em risco a possibilidade de contenção da informalidade urbana.
\end{abstract}

P A L A V R A S - C H A V E : produção habitacional; inclusão urbana; informalidade urbana; zoneamento includente; Minha Casa, Minha Vida; Fortaleza.

\section{INTRODUÇÃO}

Desde o início da década de 2000, o cenário macroeconômico brasileiro favorável e a ascensão de um governo federal comprometido com a bandeira da reforma urbana provocaram mudanças no processo de produção do espaço urbano. $\mathrm{O}$ jogo urbano passa a ter novas regras oriundas de alteraçōes nas políticas federais, com efeitos diretos na forma de produção da cidade. Dentre elas, destacam-se o Estatuto da Cidade (lei no 10.257 de 2001) e o Sistema Nacional de Habitação (lei no 11.124 de 2005). Outra importante mudança de cenário refere-se ao aumento do volume de recursos destinados à produção habitacional de baixa renda, devido, em particular, ao Programa de Aceleraçâo do Crescimento (PAC), lançado em 2007, e ao programa Minha Casa, Minha Vida (MCMV), iniciado em 2009.

O fato de que grande parte dos recursos disponíveis para a produção habitacional não passa pelo crivo do Sistema Nacional de Habitação e da Política Nacional de Desenvolvimento Urbano tem provocado questionamentos, entre acadêmicos, sobre a eficácia da aplicação desses investimentos no combate ao deficit habitacional 
(ROLNIK; NAKANO, 2009; BRASIL, 2009). O argumento central desse modelo de análise é que os programas governamentais com grande volume de recursos isto é, o PAC e o MCMV - pressupóem que os municípios se fortaleçam institucionalmente para exercer o papel de formulador e executor da política fundiária e urbana, determinando os locais destinados prioritariamente à habitação de interesse social. No entanto, os programas não requerem tal capacidade institucional como condição para a realização do investimento. Por causa dessa fragilidade, os interesses dos agentes ligados ao mercado imobiliário acabam prevalecendo sobre o interesse coletivo no processo de produção do espaço urbano acessível a todas as camadas da população.

Inserido nessa discussão, este artigo, de modo a identificar os avanços e retrocessos das mudanças elencadas acima, avalia a produção habitacional na Região Metropolitana de Fortaleza na última década, enfatizando o programa Minha Casa, Minha Vida. Na primeira parte, é-se sistematizada a literatura a respeito das políticas habitacionais urbanas brasileiras e seus impactos na organização espacial das metrópoles. Identifica-se, na literatura, um questionamento da política habitacional vigente relacionado à falta de articulação dos programas habitacionais com a política urbana e, especificamente, com seu objetivo de inclusão socioespacial por meio do combate ao aumento especulativo do preço da terra urbana infraestruturada. Já na segunda, é-se revelada como essa desarticulação opera no processo de produçáo do espaço urbano da Regiáo Metropolitana de Fortaleza (RMF). Essa parte se apoia em um sistema de informaçôes geográficas, utilizando dados da produção imobiliária de diversas fontes, como Caixa Econômica Federal (CEF), Instituto Brasileiro de Geografia e Estatística (IBGE) e Sindicato da Indústria da Construção Civil (SINDUSCON).

Concernente ao método escolhido, ressalte-se que ele permitiu avaliar a localização dos produtos imobiliários por faixa de renda. Complementando os mapeamentos produzidos, foram realizadas entrevistas com atores-chave no processo de implementação dos programas habitacionais. Uma terceira fonte de dados foi o levantamento na imprensa local de informaçôes sobre o curso do programa Minha Casa, Minha Vida.

\section{MUDANÇAS RECENTES NA POLÍTICA HABITACIONAL E URBANA NO CONTEXTO BRASILEIRO}

\section{PoLítica habitacional E SEgRegaçÃo SOCIOESPACIAL ATÉ A DÉCADA DE 2000}

Ao longo das décadas de 1970 e 1980, as grandes metrópoles brasileiras tinham em comum a existência de uma periferia cuja população vivia em condiçôes visivelmente inferiores àquelas oferecidas nos bairros mais centrais, o que produziu o conhecido modelo de segregação socioespacial centro-periferia. A política habitacional desse período, que corresponde à vigência do Banco Nacional de Habitação (BNH), é frequentemente apontada como um importante fator de indução de tal forma de organização espacial. Os programas habitacionais do banco transferiam os moradores de assentamentos precários de uma área efetivamente urbanizada 
para grandes conjuntos localizados além das fronteiras da cidade e, portanto, em áreas desprovidas de serviços urbanos ${ }^{1}$. Essa prática não apenas induzia um modelo de segregação centro-periferia, mas também expandia, demasiadamente, o tecido urbano, gerando altos custos para a gestão do território. As críticas à expansão excessiva do tecido urbano direcionaram-se, principalmente, às dificuldades em racionalizar os investimentos em infraestrutura urbana. Tal modelo de produçáo de cidade também é descrito como "urbanização em saltos", devido à grande incidência de áreas desocupadas, situadas entre o centro rico e a periferia pobre. Estender as redes de serviços urbanos e, em especial, de transportes para os grandes conjuntos habitacionais periféricos implicava, necessariamente, beneficiar os proprietários das áreas intermediárias, os quais eram grandes proprietários imobiliários que se apropriavam de investimentos públicos em um processo conhecido como retenção especulativa de terrenos (BONDUKI, 1998).

A partir da década de 1990, o modelo de segregação centro-periferia começa a apresentar sinais de enfraquecimento. A literatura aponta importantes mudanças na questão da desigualdade e segregação na metrópole contemporânea, dentre as quais se destaca a complexificação do padrão de distribuição da qualidade ambiental urbana, com vistas a uma maior fragmentação do tecido urbano (RIBEIRO; LAGO, 1994). Esse processo revela-se de duas formas. Em primeiro lugar, observa-se uma maior diversificação social das áreas periféricas, até então exclusivas de setores de baixa renda, dada a emergência de novos padróes de segregação das classes médias e altas, os condomínios fechados. Em segundo, verifica-se a difusão da pobreza por todo o tecido urbano e, sobretudo, a explosão populacional das favelas em áreas providas de acessibilidade, mas situadas em terrenos impróprios à ocupação urbana, como alagados, encostas, faixas de domínio de concessionárias públicas, dentre outros.

Vale ressaltar que a alternativa da ilegalidade urbana não atingiu apenas as classes baixas (até 3 salários mínimos), mas também a classe média (3 a 10 salários mínimos). O fim do Sistema Financeiro de Habitação na década de 1980 contribuiu para um processo de elitização da produção imobiliária formal privada, o que resultou na redução de oferta de imóveis urbanos para a classe média. Como consequência, ela passou a ocupar, crescentemente, loteamentos irregulares e até mesmo favelas urbanizadas. A falta de atendimento ao mercado habitacional da classe média tem sido apontada como um fator que inviabilizou o atendimento do deficit habitacional de baixa renda (MARICATO, 2005).

A drástica redução da produção habitacional de larga escala a partir dos anos 1980 e o cenário macroeconômico desfavorável estimularam o processo de favelização e a crescente ilegalidade apresentados nesse período. No entanto, o cenário macroeconômico negativo modificou-se a partir do ano 2000, acompanhado de alteraçóes na condução das políticas habitacionais e urbanas brasileiras.

\section{A ATUAL POLÍTICA HABITACIONAL BRASILEIRA}

No início da década de 2000, os fatores que atuavam sobre o processo de produção da informalidade urbana brasileira sofrem significativas alteraçôes. Com a ascensão política do Partido dos Trabalhadores (PT) ao governo federal em 2002, inicia-se um processo nacional de institucionalização das políticas urbanas e habitacionais. Após a estruturação do Ministério das Cidades e a instituição do Conselho
1 Ressalte-se, entretanto, importantes diferenças na condução dessas políticas entre municípios brasileiros. Por exemplo, no caso de Fortaleza, diferente do Rio de Janeiro, os conjuntos habitacionais não eram destinados apenas a moradores de assentamentos precários. 
das Cidades em 2003, consolida-se um processo de construçáo de uma nova política habitacional, aprovada em 2004 e seguida pela instituição de um Sistema Nacional de Habitação de Interesse Social (SNHIS) em 2005. Dentre os quatro eixos de atuação da Política Nacional de Habitação (PNH), destaca-se o eixo da habitação de mercado, que tinha como principal objetivo gerar estímulos para que o mercado imobiliário privado aumentasse a atuação na produção habitacional para a classe média e média baixa, combatendo um processo de elitização intensa da produção imobiliária formal vigente nas décadas anteriores. Como exemplos de medidas nessa direção, sobressaem a edição das Leis Federais no 10.391/2004, 11.033/2004 e 11.196/2005, que conferiram maior segurança jurídica ao financiamento e à produção de habitação de mercado, e a Resolução do Conselho Monetário Nacional (CMN), em 2005, que obrigou os bancos a investirem em financiamento habitacional uma porcentagem de recursos captados por meio do Sistema Brasileiro de Poupança e Empréstimo (SBPE), revogando as resoluções que permitiam a aplicação de tais recursos em títulos da dívida pública depositados no Banco Central (MARICATO, 2005). Como resultado da nova política habitacional, nota-se um aumento de financiamentos imobiliários para aquisição, reforma ou construção de novas moradias.

Gráfico 1: Evolução dos financiamentos habitacionais pessoa física para aquisição, reforma ou construção de novas moradias - FAR/FGTS/SUBSÍDIOS/ FDS, em R \$ bilhóes

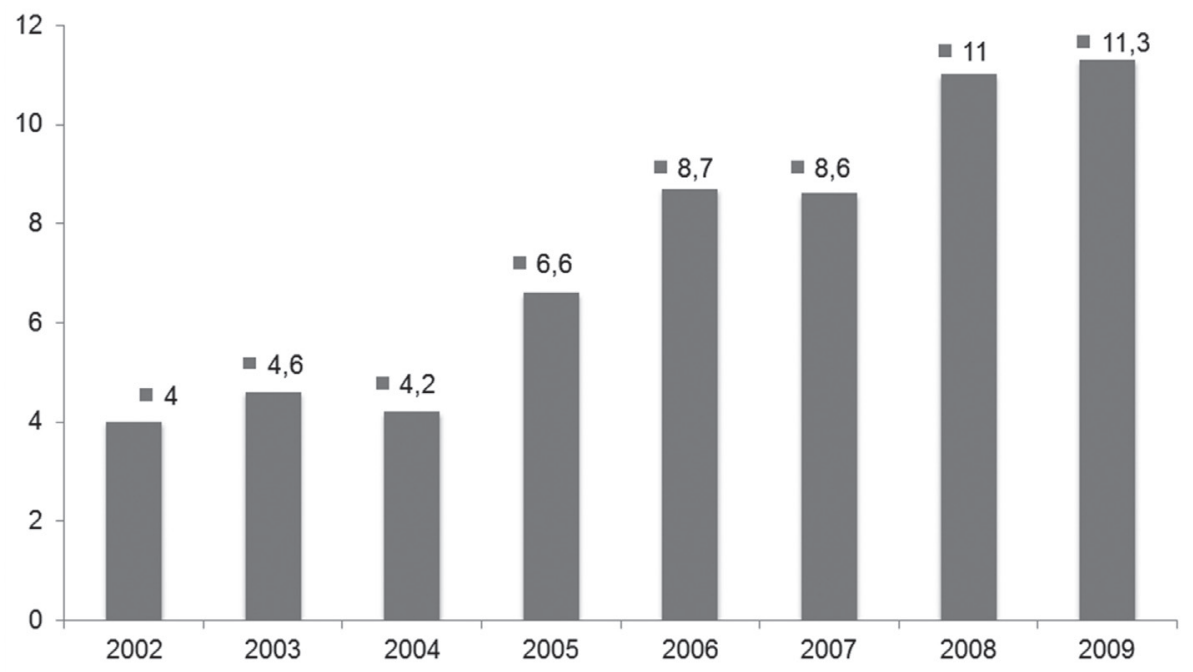

Fonte: Chaves (2009). Dados atualizados da Casa Civil (Disponível em: <http://www.casacivil. gov.br/uploads/06.pdf>. Acesso em: 5 abr. 2015).

Tais medidas visam a estimular a produção imobiliária formal para camadas de renda intermediárias que antes tinham dificuldade de acessar esse mercado - esforço que possui estreita relação com o problema do deficit habitacional de baixa renda, pois a falta de alternativa habitacional para a classe média inflaciona o preço dos produtos disponíveis para a classe baixa, alimentando processos de gentrificação. No Brasil, utilizam-se também os termos "expulsão de mercado" ou "expulsão branca" ao processo de substituição da população-alvo dos programas de habitação de interesse social ou urbanização de assentamentos precários por uma camada de renda 
imediatamente superior. Assim, quando o mercado imobiliário formal não produzir empreendimentos para a classe $\mathrm{C}$, esta se vê atraída pelas opçóes de moradia destinadas às classes inferiores, produzidas por programas habitacionais para a baixa renda. $\mathrm{O}$ mercado informal se encarrega de transformar tal interesse em um aumento dos preços dos produtos, que se tornam, portanto, indisponíveis para a população -alvo dos programas habitacionais.

Um dos objetivos da política habitacional aprovada em 2004 é criar condiçôes favoráveis ao mercado imobiliário formal para produzir para a classe C, combatendo o processo de gentrificação nas favelas urbanizadas. Tal objetivo já constava no programa de governo do entáo candidato à Presidência da República Lula, eleito em 2002. Entretanto, aos poucos, a meta de criar condiçóes para o atendimento ao deficit de baixa renda, dá lugar às demandas de atores políticos ligados à agenda do mercado imobiliário, que se tornam atuantes no cenário de estabilização da inflação e crescimento econômico.

\section{CRÍTICA À POLÍTICA HABITACIONAL: A QUESTÃO FUNDIÁRIA}

Contradizendo o cenário positivo descrito até aqui, a literatura sobre estudos urbanos brasileiros tem apontado fatores que talvez comprometam os objetivos esperados da nova política habitacional (MARICATO, 2009; ROLNIK; NAKANO, 2009). Assinale-se, por exemplo, a timidez no enfrentamento da questáo fundiária urbana. Para explicar essa questão, é necessário voltar às origens da atual política urbana brasileira.

A política urbana brasileira sofre uma importante mudança de rumos no início da década de 2000. Com a aprovação do Estatuto da Cidade, em 2001, inicia-se um processo de renovaçáo do marco legal urbano, com vistas a contrapor-se aos efeitos de exclusão socioespacial da legislação vigente. A renovação atua basicamente em três campos: (1) Regularização fundiária, que assegura o direito à moradia aos habitantes de assentamentos consolidados; (2) Indução do desenvolvimento urbano includente, que visa a combater a valorização imobiliária especulativa, enfrentando uma das maiores deficiências da política urbana brasileira; (3) Democratização da gestão territorial, a fim de permitir controle social das decisóes de planejamento.

O Estatuto da Cidade estabelece instrumentos de viabilizaçâo para cada uma das três estratégias de atuação, os quais podem ser utilizados pelos municípios a partir da renovação dos planos diretores municipais. Durante os últimos 10 anos de atualização das políticas urbanas municipais, percebe-se que, dentre os instrumentos do Estatuto, aqueles de mais difícil implantação são justamente os que objetivam combater a valorizaçáo imobiliária, como o IPTU Progressivo e as Zonas Especiais de Interesse Social (ZEIS) de vazios (OLIVEIRA; BIASOTTO, 2011). O IPTU progressivo torna desvantajoso para o proprietário a retenção especulativa de terra infraestruturada e incentiva o aumento da oferta de terrenos no mercado imobiliário, o que incita o rebaixamento do preço da terra urbana. As "ZEIS de vazios" atuam no âmbito das regulaçóes edilícias, proibindo o estabelecimento de padróes arquitetônicos e urbanísticos característicos de classes médias e altas.

O pouco avanço na implementação dos instrumentos de combate ao aumento especulativo do valor dos terrenos urbanos infraestruturados leva a uma contradição: o poder público investe esforços e um enorme volume de recursos para reduzir o 
passivo urbanístico criado por uma lógica de produção de cidade excludente sem que essa mesma lógica seja alterada. Por "lógica de produção de cidade excludente", entenda-se o modo de urbanização que não dá alternativa de acesso à moradia para as classes média e baixa, restando à população de baixa renda submeter-se a aluguéis com preços abusivos ou comprar/ocupar imóveis em assentamentos informais, alimentando o ciclo vicioso da informalidade urbana.

A urbanização dos atuais assentamentos precários representa um custo altíssimo, que poderia ter sido evitado se a política urbana das décadas anteriores tivesse sido capaz de incluir a população de baixa renda na cidade que estava sendo produzida pelo mercado imobiliário formal. Nesse sentido, as políticas de regularização tornam-se ineficazes, se o poder público não atua na principal causa da informalidade: a impossibilidade de produzir imóveis a preços acessíveis em bairros dotados de serviços básicos e próximos a zonas que concentram empregos. Tal impossibilidade possui relaçáo direta com o aumento especulativo do preço dos terrenos nos bairros bem localizados, fato que inviabiliza a construção da habitação de interesse social em bairros adequados.

Infelizmente, na conjuntura política atual, quando o mercado imobiliário dispóe de condiçôes favoráveis para ampliar-se na direção das classes intermediárias, observa-se que as políticas urbanas locais não têm sido capazes de viabilizar a produção imobiliária de baixo custo em um espaço efetivamente urbanizado. Abdicar de intervir no processo de formação do preço da terra urbana significa deixar para o mercado a tarefa de resolver a localização dos novos empreendimentos habitacionais para as faixas de renda mais baixas. Considerando isso, corre-se o risco de reviver um modelo de expulsão da populaçáo para bairros periféricos e desprovidos de serviços, aplicado pela política do BNH até a década de 1980. Para Rolnik e Nakano (2009), esse risco é um fato. Eles descrevem o pacote habitacional federal Minha Casa, Minha Vida como um exemplo de uma ação contraditória do governo federal ao induzir o aumento da demanda por terrenos infraestruturados sem requerer o uso dos mecanismos de ampliação do acesso à terra para a baixa renda (ROLNIK; NAKANO, 2009).

As mudanças recentes possuem aspectos positivos, como o estímulo à produção de mercado para classes intermediárias, por meio de financiamentos ao comprador e aos empreendimentos habitacionais para faixas de rendas intermediárias. No entanto, elas também fazem acender um sinal de alerta, isto porque, no atual contexto político nacional, não existem garantias de que a política habitacional será implementada em concordância com a política urbana. Desenha-se um cenário em que a questão fundiária urbana pode, mais uma vez, ser deixada de lado. Um contexto no qual o simples aumento da demanda por terrenos infraestruturados, promovido pelo lançamento do pacote habitacional, inviabiliza a produção para as classes $\mathrm{C}$ e $\mathrm{D}$ nos bairros providos de serviços urbanos. Como resultado, os investimentos da política habitacional dão-se em áreas desconectadas dos serviços urbanos básicos, acarretando a valorização dos vazios urbanos e a transferência da mais-valia fundiária urbana (gerada por investimentos públicos) para proprietários privados. A política pública de habitação corre o risco de alimentar um ciclo vicioso de valorização imobiliária e exclusão social, em vez de combatê-lo.

Tendo como pano de fundo a relação entre a política habitacional e a questão fundiária, analisa-se, a partir daqui, em que sentido a nova política habitacional federal proporciona avanços na disseminação do acesso à cidade, com base no estudo 
de caso da RMF. Ao investigar esse fenômeno, espera-se não apenas constatar um aumento da oferta habitacional produzida pelo mercado imobiliário formal para classes de renda intermediária, mas também se debruçar sobre a dimensão espacial do problema, buscando respostas aos seguintes questionamentos: qual a relação entre o aumento da produção imobiliária e as alteraçôes no padrão da organização territorial da cidade? Seria possível falar em periferização das camadas de baixa renda como resultado do aumento da produção habitacional?

\section{A PRODUÇÃO HABITACIONAL NA REGIÃO METROPOLITANA DE FORTALEZA NA DÉCADA DE 2000}

\section{A Região Metropolitana de Fortaleza}

A Região Metropolitana de Fortaleza é formada por $13^{2}$ municípios e possui uma população de 2.984.689 habitantes, com 723.192 domicílios (IBGE, 2010). No conjunto de municípios, Fortaleza possui um significativo peso econômico e concentra $72 \%$ da população. Náo existe zona rural no município central, o que produz a falsa impressão de inexistência de terra disponível para produção habitacional de baixa renda, tradicionalmente localizada nas franjas do tecido urbano. Essa impressão pode ser questionada se se leva em consideração a existência de vazios urbanos. Como na maior parte das grandes cidades brasileiras, o número de domicílios vagos em Fortaleza (70 mil) aproxima-se do seu deficit habitacional (77 mil) (PEQUENO, 2009).

Apenas cinco municípios são atingidos pela mancha efetivamente urbanizada: Fortaleza, Caucaia (a oeste), Maracanaú (a sul), Eusébio (a sudeste) e Aquiraz (a sudeste). Os processos de conurbaçáo na direçấo sul e oeste foram provocados pela construção de grandes conjuntos habitacionais nos municípios limítrofes ainda na década de 1970. Já o povoamento dos bairros de Fortaleza das áreas sul e oeste por uma faixa de renda médio baixa foi incentivado, por exemplo, pela extensão das redes urbanas para atender tais conjuntos. Na década de 2000, a ampliação da malha viária na direção leste-sudeste viabilizou a construção de condomínios de classe alta, possibilitando o fenômeno da dispersão urbana das classes médias e altas para essa direçáo.

Os mapas de evolução urbana (Figura 1) revelam que o tecido urbano contínuo extrapola os limites administrativos sul e oeste do município de Fortaleza na década de 1980. Revelam ainda que, apenas a partir dos anos 2000, foram excedidas as fronteiras leste e sudeste. Existem, no entanto, diferenças no modo de produção do espaço urbano nas duas direçóes. Enquanto no vetor sudoeste a expansão urbana foi induzida pela construção de grandes conjuntos habitacionais ou loteamentos clandestinos e autoconstrução rumo aos dos municípios de Maracanaú e Caucaia, o crescimento da malha urbana no vetor sudeste está sendo estimulado pela expansão da malha viária regional, com maior atuação do mercado imobiliário formal.

\footnotetext{
2 Em novembro de 2009, o governo do estado incluiu mais dois municípios na $\mathrm{Re}$ gião Metropolitana, Cascavel e Pindoretama. Este trabalho considera apenas os $13 \mathrm{mu}$ nicípios anteriores à mudança, uma vez que a inclusão ainda não está consolidada, tendo sido inclusive questionada por setores da própria administração estadual. Posteriormente, em 2014, mais 04 municípios foram incorporados: Paracuru, Paraipaba, Trairi e São Luis do Curú.
} 
Figura 1: Região Metropolitana de Fortaleza: divisão político-administrativa e evolução da mancha urbana

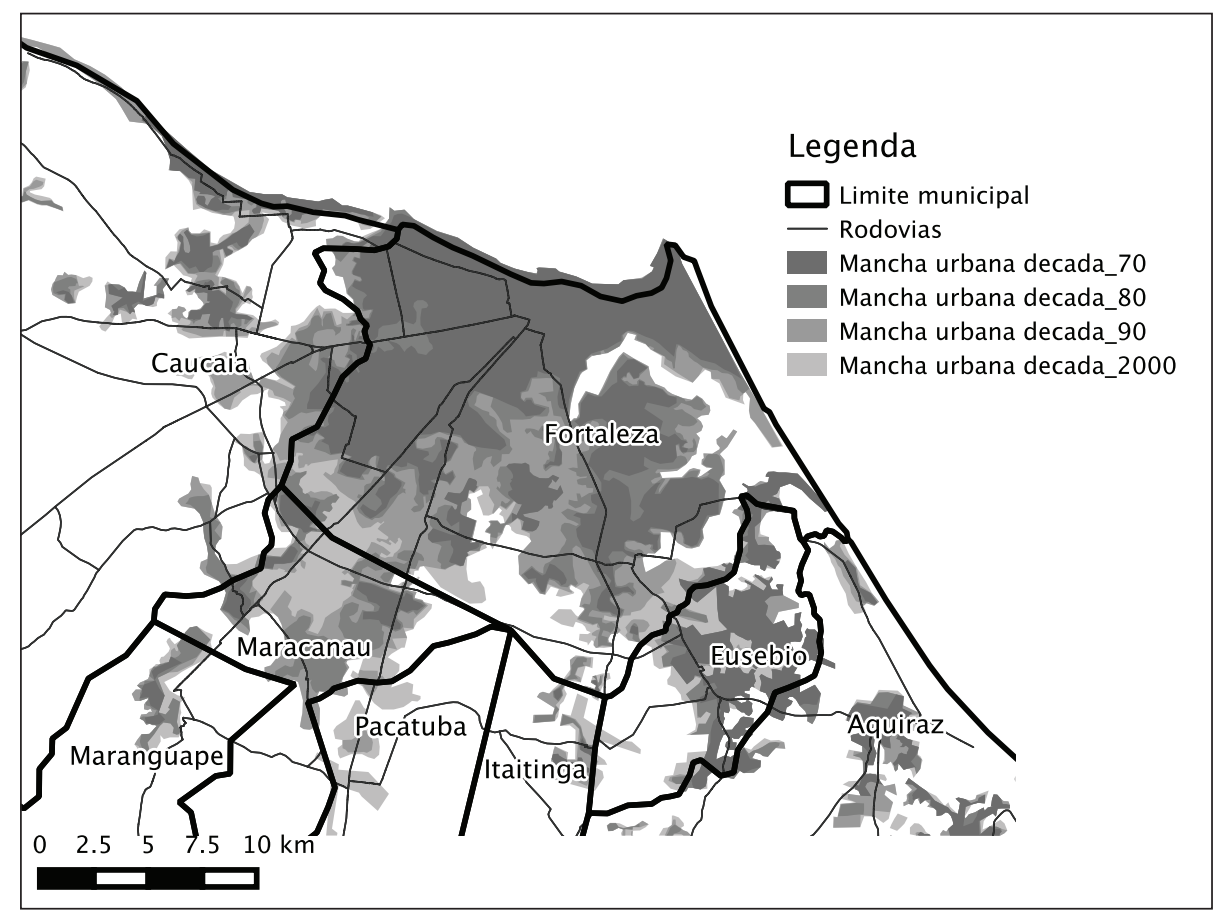

Fonte: Elaborado por Clarissa Freitas a partir de dados do Observatório das Metrópoles (2010).

3 Maracanaú e Caucaia, os dois municípios mais populosos, por exemplo, aprovaram seus planos urbanos em 2000 , os quais praticamente não mencionam as diretrizes de inclusão territorial do Estatuto da Cidade.

Assim como a população, a capacidade institucional de planejamento territorial dos municípios também é desigualmente distribuída na RMF. Poucos deles atualizaram seus planos diretores após a aprovaçáo do Estatuto da Cidade em 2001, tendo em vista que o governo estadual havia financiado a elaboraçáo de vários planos municipais no final da década de 1990 por meio do programa PROURB ${ }^{3}$. Apenas o município de Fortaleza inicia um processo de revisão do Plano Diretor no começo da década de 2000. Todavia, em 2005, com a mudança de orientaçáo da política local devido à acensão do PT na gestão municipal, é retirada a proposta de plano enviada à Câmara Municipal pela gestáo do PMDB, fundamentada na ausência de participação popular em seu processo de elaboração. Assim, em 2005, inicia-se uma fase de repactuação do Plano Diretor de Fortaleza, atualmente denominado Plano Diretor Participativo (PDP), cuja versão final foi aprovada em fevereiro de 2009. Esse período de discussão do PDP é marcado pela disputa por terra urbanizada entre os diversos atores. Assinale-se, dentre outras, a açáo dos agentes ligados ao mercado imobiliário e dos movimentos sociais de moradia. Este últimos concentram-se em torno da demanda pela aprovação das ZEIS em áreas bem dotadas de serviços e infraestrutura urbana, enquanto os setores ligados à produção imobiliária formal defendem o aumento de indices contrutivos, potencializando a valorizaçáo imobiliária dos terrenos melhor servidos por redes de infraestrutura. Tal valorização, como será visto, impóe mais incentivos para a periferização da provisão habitacional de mercado; ao mesmo tempo, as condições políticas para a implementação das ZEIS deterioram-se como resultado de uma crescente atuação do governo local em benefício do setor imobiliário. 


\section{A PRODUÇÃO IMOBILIÁRIA FORMAL}

A partir dos dados dos relatórios mensais de velocidade de vendas do Sinduscon$\mathrm{CE}$, pode-se inferir, por um lado, que o mercado imobiliário formal corresponde a uma parcela muito pequena da produção imobiliária da Região Metropolitana de Fortaleza, com forte concentração espacial nos bairros onde estão localizadas as faixas de renda superiores (classes A e B). Por outro, os mesmos dados revelam que a produção imobiliária da RMF tem apresentado um movimento de expansão nos anos finais da década de 2000. Nos gráficos abaixo, nota-se um aumento no número total de lançamentos imobiliários nos últimos três anos.

Gráfico 2: Evolução do número de lançamentos imobiliários na Regiáo Metropolitana de Fortaleza: dados amostrais de empresas afiliadas ao Sinduscon-CE

Total lançamentos imobiliários -Fortaleza

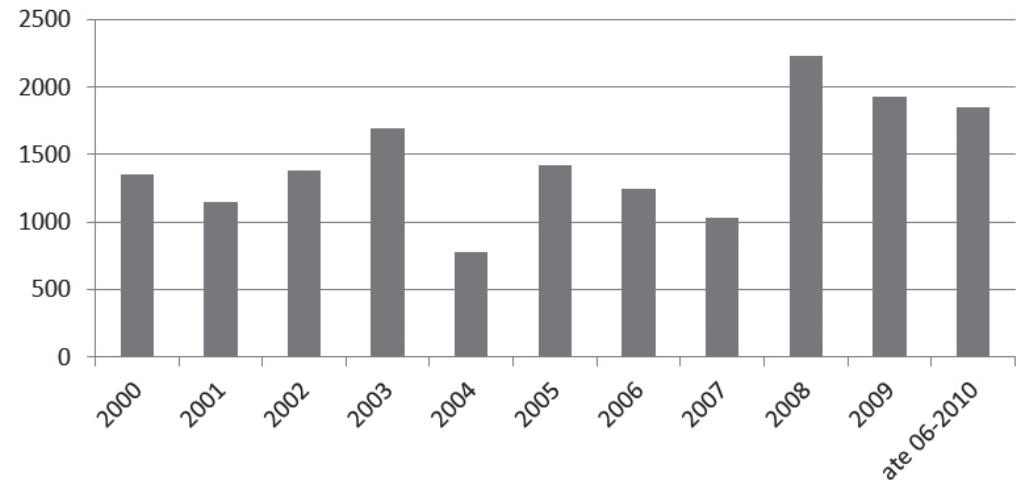

Numero de UHs ofertadas para a faixa de 5 a $10 \mathrm{SM}$ em fevereiro

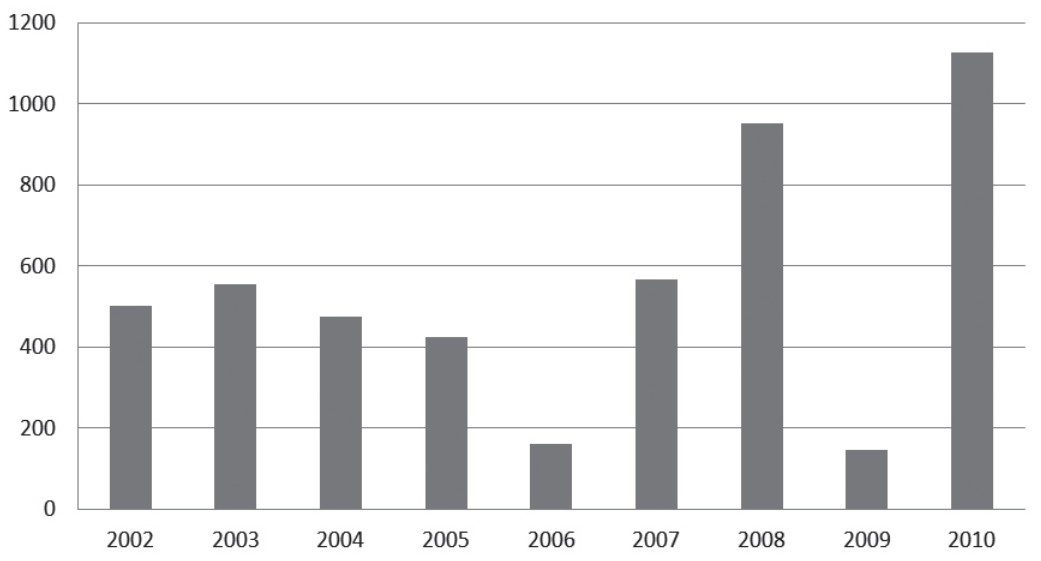

Fonte: Sistematizado pelos autores com base em IEL-FIEC e Sinduscon (2010).

Os dados das empresas afiliadas ao Sinduscon revelam, ainda, que, a partir de meados da década de 2000, a produção imobiliária para a classe C volta a crescer - excetuando-se 2009, ano de crise econômica. A impressão é confirmada nas entrevistas realizadas com empreendedores que atuam nesse mercado e com agentes da Caixa Econômica Federal ${ }^{4}$. O aumento da oferta de financiamentos imobiliários e

4 Entrevista realizada com - Sr. André Montenegro proprietário da Construtora More Fácil em 22 de abril de 2010. 
a segurança jurídica para as empresas produtoras são apontados como o principal fator de estímulo para o movimento de deselitização do mercado imobiliário local, ratificando uma afirmação encontrada na literatura nacional (MARICATO, 2005).

A expansão do mercado imobiliário formal para todas as faixas de renda e mais especificamente, o aumento da produção imobiliária para a classe $\mathrm{C}$ são aspectos extremamente positivos no cenário de exclusão territorial existente na RMF. Tais tendências, se confirmadas, indicaria um aumento da produção imobiliária formal com relação ao total da produção imobiliária da RMF, o que, em contrapartida, acarretaria a diminuição do peso da informalidade urbana.

Entretanto, esse cenário positivo começa a ficar menos evidente quando se analisa a questáo da distribuição espacial dos empreendimentos destinados às faixas de renda inferiores. Tradicionalmente, o mercado imobiliário tem atuado numa porção relativamente restrita do território urbanizado, concentrando suas atividades nos bairros adjacentes à zona central, no vetor leste-sudeste e no espaço litorâneo, onde a atividade turística e a demanda das classes altas por segunda residência fomentam a produção de mercado na área.

A produção imobiliária para o público-alvo de 5 a 10 salários mínimos (SM) não tem acontecido nos bairros onde o mercado elitizado normalmente atua. $\mathrm{O}$ material coletado sugere que o aumento da produção imobiliária para esse mercado tem-se dado em bairros menos tradicionais, fora do eixo leste-sudeste. Uma reportagem publicada em um jornal local em novembro de $2009^{5}$ destaca isso, citando como exemplos os bairros de Messejana, Passaré, Castelão, Modumbim e Maraponga, que apresentam empreendimentos na faixa de 90 a 130 mil reais na forma de condomínios fechados. Segundo a reportagem, a procura por esses bairros, classificados no texto como "emergentes", deve-se à dificuldade de adquirir terrenos nos bairros tradicionais da zona leste sudeste. Nessa área mais valorizada, o preço dos terrenos vagos inviabiliza a produção para o mercado da classe $\mathrm{C}$ e torna vantajosa somente a produção de unidades luxuosas vendidas para faixas de renda superiores.

Diante da dificuldade de mapear as informaçōes sobre a produção imobiliária coletada das empresas afiliadas ao Sinduscon, avaliou-se os dados referentes aos financiamentos à produção imobiliária do escritório de negócios da Caixa Econômica Federal em Fortaleza. A espacialização dos empreendimentos aptos a receber financiamentos habitacionais na RMF na década de 2000 revela a tendência de periferização dos locais de moradia das classes de renda inferiores. $\mathrm{O}$ mapeamento dos dados (Figura 2) não deixa dúvidas em relação ao padrão de localização espacial dos empreendimentos por faixa de renda: quanto menor o público-alvo do empreendimento, mais periférica é sua localização.

O mapeamento dos dados da CAIXA legitima o cenário descrito pela reportagem: a reserva de terrenos em bairros "nobres" para uma faixa de renda acima de 10 SM faz com que a produçáo imobiliária para as faixas de 3 a 10 SM se dê em bairros "emergentes". Como consequência, a produção para a faixa abaixo de 3 SM enfrenta dificuldades de ser realizada dentro dos limites administrativos do município de Fortaleza, sendo empurrada para os municípios vizinhos. A análise do andamento do programa Minha Casa, Minha Vida (MCMV) na próxima seção ilustra esse fenômeno. 
Figura 2: Empreendimentos aptos a receber financiamentos habitacionais na RMF, década de 2000

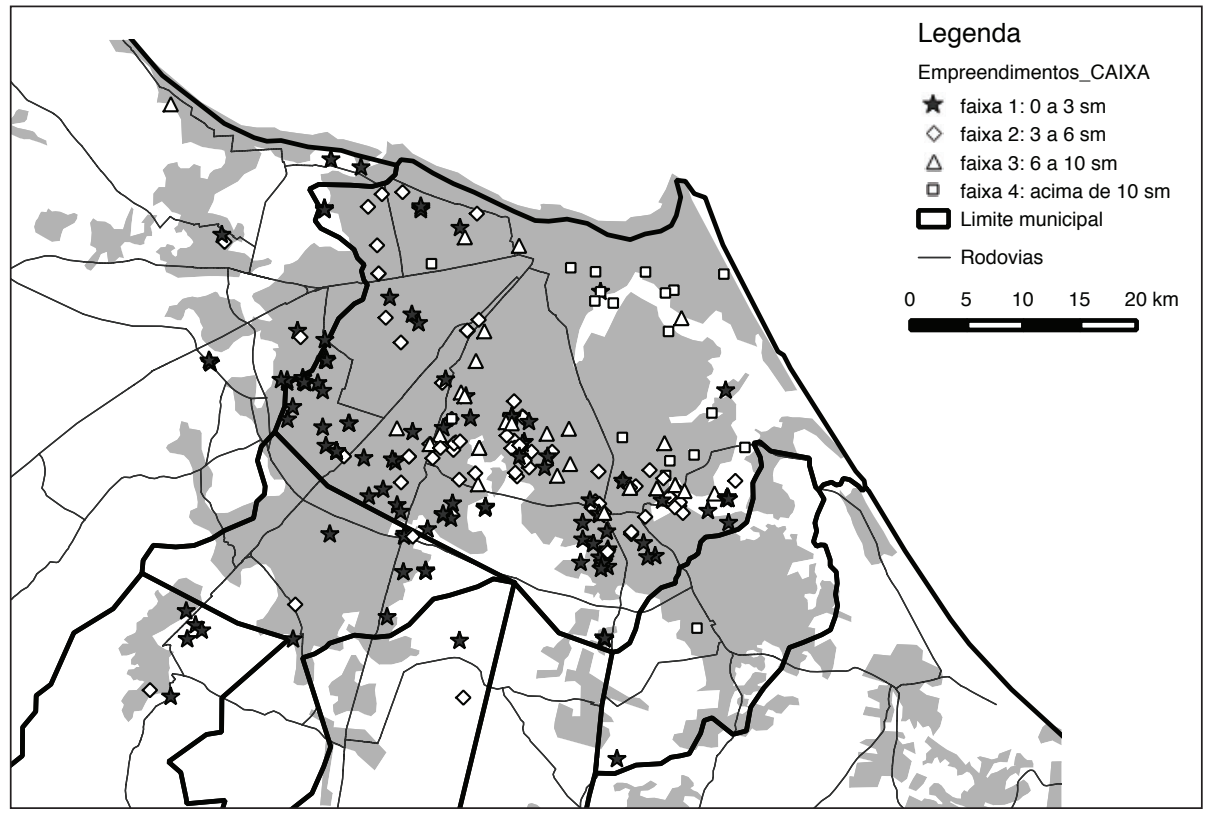

Fonte: Sistematizado por Clarissa Freitas com base em CEF/GIDUR-CE.

\section{O MCMV E A PRODUÇÃo PARA A FAIXA DE O A 3 SALÁRIOS MíNIMOS}

Com o lançamento do programa habitacional Minha Casa, Minha Vida em 2009, a falta de alternativa para a produção de moradia de baixa renda em bairros dotados de infraestrutura ficou bastante evidente e passou a ocupar as páginas dos jornais locais no início de 2010. De fato, em um primeiro momento, a execução do programa para a faixa de 0 a 3 salários mínimos no município de Fortaleza ficou muito abaixo do esperado. A explicação para a dificuldade inicial era clara: os terrenos dotados dos serviços urbanos requeridos pelo programa localizavam-se apenas nas áreas muito valorizadas, cujo preço inviabilizava a produção de unidades habitacionais de até 45 mil reais, como previa o programa ${ }^{6}$.

A Figura 3 traz a localização dos empreendimentos aprovados ou em análise pela Caixa para a faixa de renda de até 3 salários mínimos até dezembro de 2012. Percebe-se uma concentração de empreendimentos na direção sul-oeste, onde a terra é mais barata e a acessibilidade ao centro pior que na zona leste. O mapa revela, ainda, que a maior parte dos empreendimentos do Minha Casa, Minha Vida para a faixa de renda inferior localiza-se nos limites da mancha efetivamente urbanizada: isso sinaliza, em certa medida, um processo de dispersão urbana, induzido por conjuntos habitacionais de baixa renda, muito semelhante ao que aconteceu no período de vigência do $\mathrm{BNH}$.

6 Ver, por exemplo, a reportagem de 17 de abril de 2010 do Jornal O Povo (CEARÁ, 2010). 
Figura 3: Empreendimentos do Minha Casa, Minha Vida na faixa de 0 a 3 SM aprovados ou em análise pela CEF/Gidur-CE, dezembro de 2012

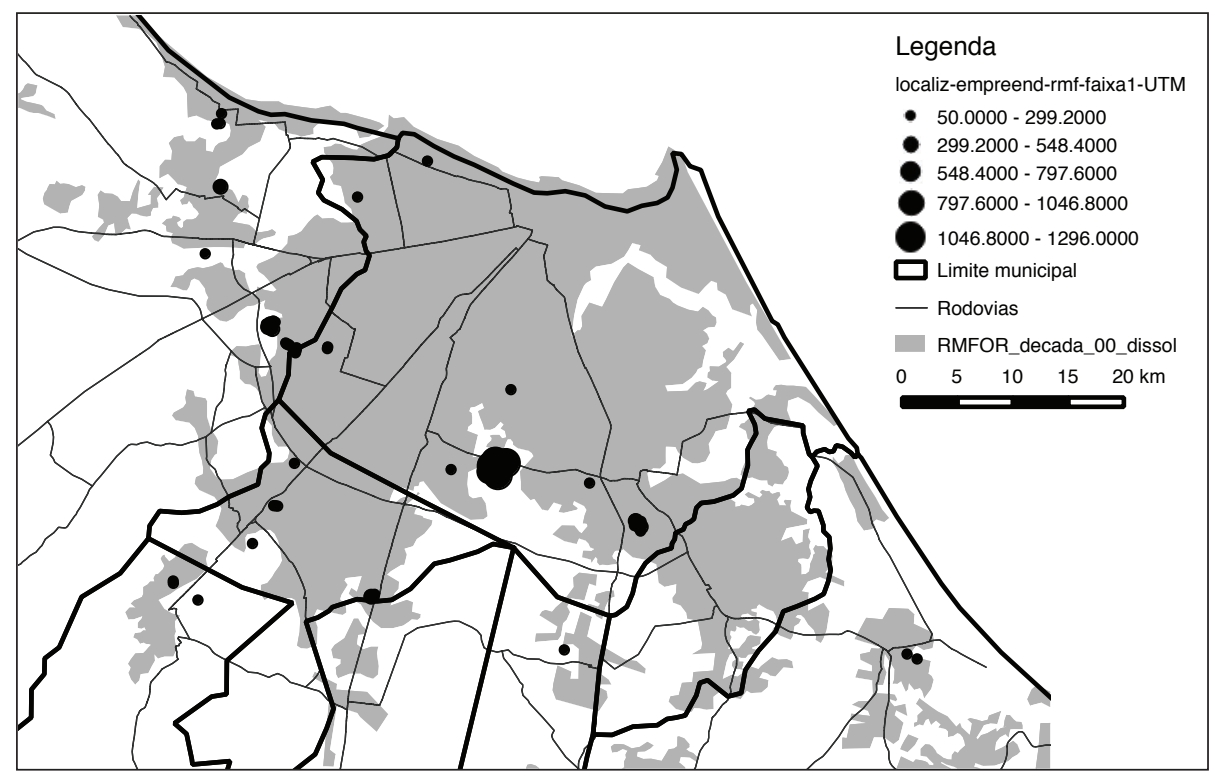

Fonte: Sistematizado por Clarissa Freitas com base em CEF/Gidur-CE.

A pequena concentração de empreendimentos nos bairros dotados de infraestrutura e serviços do município de Fortaleza pode ser atribuída ao alto preço da terra. Nos outros bairros - aqueles de localização periférica -, a quase inexistência de empreendimentos deve-se também a uma restrição da legislação ambiental municipal. Tal restrição impedia a instalação de conjuntos de habitação de interesse social em áreas não dotadas de redes de esgotamento sanitário e sem previsão do serviço no prazo de 5 anos. Em março de 2010, em resposta à pressão política dos atores

7 A esse respeito, ver reportagem no portal da Secretaria das Cidades do Estado do Ceará (COEMA, 2010).

8 Entrevista realizada pelo programa Rádio Debate, na Rádio Universitária da UFC, no dia 07 de abril de 2010. interessados no andamento do programa habitacional em Fortaleza ${ }^{7}$, uma alteração na resolução do COEMA que tratava desse aspecto flexibilizou a norma A solução de diminuir os requerimentos de infraestrutura foi aprovada por todos os setores envolvidos no programa, inclusive por atores ligados aos movimentos sociais de moradia que não viam sentido na exigência. Esta lhes parecia demasiadamente sem sentido e representava um obstáculo ao andamento do programa, não uma forma de garantir a inserção urbana dos empreendimentos de baixa renda.

No debate acerca da execução do programa em Fortaleza, todos os atores veem o alto preço dos terrenos como um entrave a seu andamento, porém nenhum deles menciona os instrumentos de combate à especulação imobiliária como uma possível solução. Um representante da $\mathrm{CEF}$, numa entrevista à radio universitária ${ }^{8}$ em que se discutia o andamento do MCMV, chegou a falar em um aumento de cerca de $30 \%$ no preço dos terrenos em Fortaleza como resultado do crescimento da demanda por terrenos provocado pelo lançamento do programa. A mesma informação, apesar de não ter sido embasada em nenhum levantamento sistematizado, aparece também em algumas reportagens na impressa local. Em novembro de 2009, um jornal de grande circulação afirmava que "[o]s aproximadamente $313 \mathrm{~km}^{2}$ de Fortaleza parecem poucos para abrigar os anseios gerados pelo bom momento do setor imobiliário. Bairros que eram apenas "de periferia” ganham nichos populacionais organizados" (PROCURA, 2009, n.p.). 
O fenômeno de valorizaçáo imobiliária como resultado da maior demanda por terrenos dotados de infraestrutura poderia ter sido contido com a aplicação dos instrumentos de combate à especulação imobiliária. Em janeiro de 2009, o Plano Diretor de Fortaleza criou os instrumentos das ZEIS vazias e do IPTU progressivo. As ZEIS vazias já estão delimitadas e são definidas como perímetros onde a habitação de interesse social deve ser o uso predominante. Contudo, a falta de regulamentação do instrumento faz com que os terrenos localizados dentro desses polígonos ainda possuam preços inacessíveis para a construção de HIS (Habitação de Interesse Social). O resultado é que não há empreendimento de HIS do MCMV localizado em área destinada pelo plano diretor para esse uso.

O Instrumento do IPTU progressivo também teria o potencial de combater o aumento do preço dos terrenos descritos anteriormente. A localização periférica dos empreendimentos da faixa de 0 a 3 SM do programa MCMV contrasta com a realidade de vários bairros "nobres" ou "emergentes" que acumulam vazios há décadas. Um exemplo é o bairro Cidade dos Funcionários na zona leste de Fortaleza, que possui $16,3 \%$ de sua área loteada completamente vazia ${ }^{9}$, o que corresponde a aproximadamente 35 hectares de lotes vazios. Isto é particularmente grave se se considera que o bairro foi loteado, em sua maioria, na década de 1950, portanto, há praticamente 60 anos. Essa área permanece vazia à espera da ampliação do mercado das classes A e B, o qual é muito restrito se comparado ao total da populaçáo urbana. Se fosse aplicado nesse bairro o IPTU Progressivo, haveria, provavelmente, o aumento da oferta de terreno dotado de infraestrutura e, por consequência, o rebaixamento de seus preços, tornando-os financeiramente acessíveis a faixas de rendas mais baixas. A não adoção de tais instrumentos alimenta um processo perverso de superoferta de terrenos para o mercado imobiliário de alta renda, em contraposição à falta de terrenos para Habitação de Interesse Social.

Figura 4: Polígonos definidos como ZEIS vazias pelo Plano Diretor de 2009

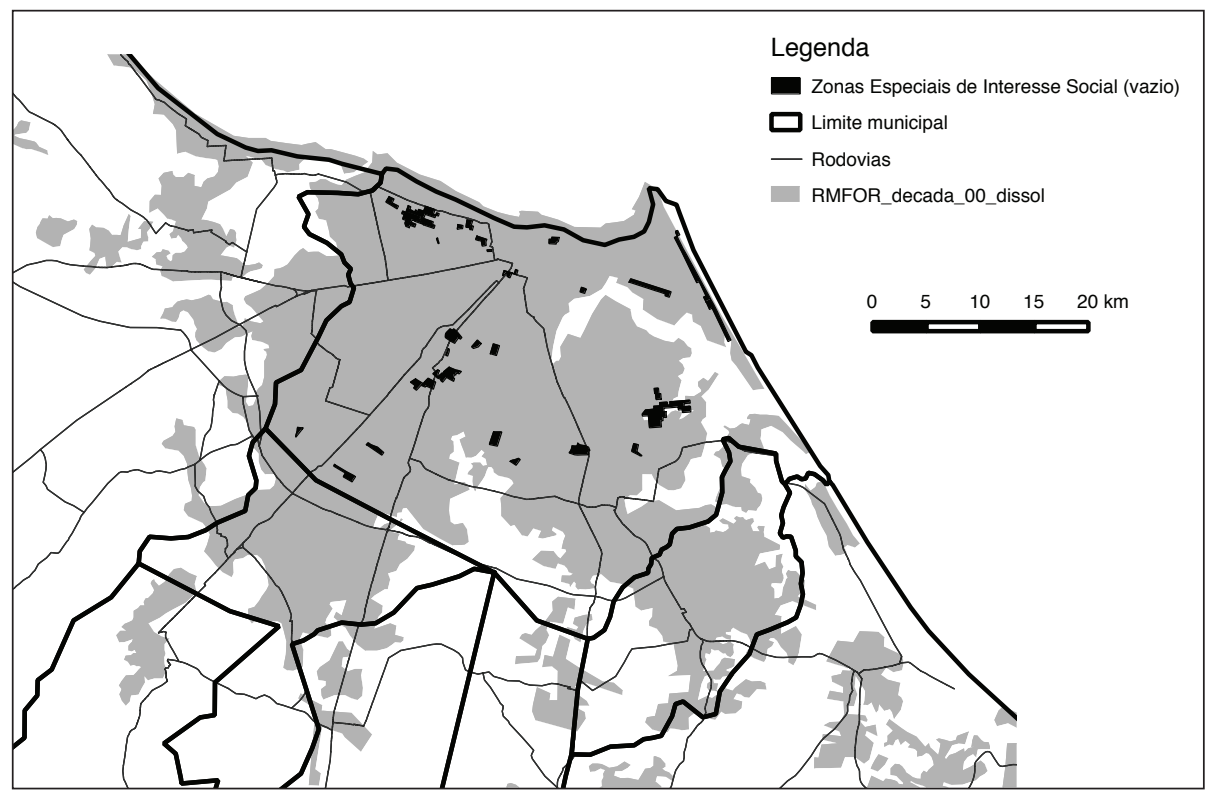

Fonte: Sistematizado por Clarissa Freitas com base no Plano Diretor Participativo de Fortaleza, Lei Complementar no 062, de 02 de fevereiro de 2009.
9 As informações sobre o bairro têm como fonte estudos não publicados, conduzidos na disciplina de Elementos de análise em Arquitetura e Urbanismo 2 (EEAU-2), do curso de Arquitetura e Urbanismo, da UFC, no segundo semestre de 2010 . 


\section{CONSIDERAÇÕES FINAIS}

Clarissa Sampaio Freitas: urbcla@gmail.com.

Luis Renato Bezerra Pequeno: renatopequeno@gmail.com.

Artigo recebido em maio de 2014 e aprovado para publicação em novembro de 2014.
O acompanhamento da produção habitacional na década de 2000 na Regiáo Metropolitana de Fortaleza permite concluir que o simples aumento da produçáo imobiliária para faixa de renda intermediária não é suficiente para combater processos de exclusão urbana das camadas menos favorecidas. Nos últimos dois anos do período analisado, o andamento do programa MCMV em Fortaleza revela um processo de periferização da moradia destinada às faixas de renda mais baixa e uma pressão por rebaixamento dos padróes de serviços urbanos para essa faixa de renda, sem que sejam cogitados mecanismos de inserção da população de baixa renda no tecido urbano dotado de melhores serviços. O fato de que o programa deixa a questáo da identificaçáo dos terrenos por conta do mercado imobiliário, aliado ao aumento da demanda por terrenos devido ao volume de recursos disponíveis, tem inviabilizado a produçấo de mercado para a população de baixa renda em áreas dotadas de serviços urbanos e acessibilidade. A análise do posicionamento dos atores envolvidos no problema revela ainda um processo de naturalização do aumento de preços de terrenos bem localizados, pois o fenômeno é sempre descrito como inevitável e fora do alcance das políticas públicas municipais.

Em última instância, o processo de produção habitacional na Região Metropolitana de Fortaleza na última década exemplifica, de forma evidente, o descolamento entre os investimentos em habitação e os objetivos da política urbana descrito pela literatura nacional. Por um lado, a política habitacional tem sido bem sucedida na ampliação do mercado imobiliário formal, até mesmo para as camadas de renda mais baixa. Por outro, o não enfrentamento da questão fundiária, via combate à especulaçáo imobiliária, pôe em risco o objetivo da contenção da proliferação de assentamentos informais em espaços inseridos na cidade.

\section{REFERÊNCIAS BIBLIOGRÁFICAS}

BONDUKI, N. Origens da habitação social no Brasil. São Paulo: Estação Liberdade; FAPESP, 1998.

BRASIL. Ministério das Cidades. $4^{a}$ Conferência Nacional das Cidades: cidade para todos e todas com gestáo democrática, participativa e controle social. Brasília: Ministério das Cidades, 2009. Disponível em: <http://www.ipea.gov.br/participacao/images/pdfs/conferencias/Cidades_IV/texto_base_4_conferencia_cidades.pdf>. Acesso em: 27 abr. 2015.

CAIXA ECONÔMICA FEDERAL. Planilha com Dados das Operaçôes de Crédito Imobiliário, CAIXA-CE desde 2000. Dados não publicados fornecidos pela GIDUR-CE em 27 de julho de 2010 .

Planilha com relação de Empreendimentos MCMV faixa de 0 a 3 SM. Dados não publicados fornecidos pela GIDUR-CE em 23 de setembro de 2010.

CEARÁ é o penúltimo no Minha Casa. O Povo, Fortaleza, 16 abr. 2010, n.p.

CHAVES, M. Q. B. Políticas e Programas Nacionais de Habitação. In: SEMINÁRIO POLÍTICAS URBANAS E REGIONAIS NO BRASIL HOJE, 2009, Brasília. Anais do Seminário Politicas Urbanas e Regionais no Brasil Hoje. Brasília: FAU/UnB, 2009.

COEMA aprova mudanças que beneficiam o programa Minha Casa, Minha Vida. Fortaleza: Assessoria de Comunicação da Secretaria das Cidades do Governo do Estado do Ceará, 21 abr. 2010. Disponível em: <www.cidades.ce.gov.br>. Acesso em: 5 abr. 2015. 
COSTA JUNIOR. E. F. Gerente de serviço de Engenharia GIDUR-CE. Entrevista semi estruturada concedida à autora em 18 de junho de 2010.

IBGE. Censo demográfico de 2010 - dados do universo. Disponível em: <http://downloads. ibge.gov.br/downloads_estatisticas.htm>. Acesso em: 26 abr. 2015

IEL-FIEC; SINDUSCON. Índice de velocidade de vendas 2000-2010. Fortaleza: IEL-FIEC; SINDUSCON, 2010. Disponível em: <www.sinduscon-ce.org.br>. Acesso em: 3 abr. 2015.

MARICATO, E. A Nova Política Nacional de Habitação. Folha de São Paulo, São Paulo, 24 nov. 2005. (Disponível em: <http://www.usp.br/fau/depprojeto/labhab/biblioteca/ textos/maricato_novapoliticahab.pdf>. Acesso em: 24 abr. 2015).

É preciso repensar o modelo. Arquitetura e Urbanismo, São Paulo, n. 186, out. 2009.

OBSERVATÓRIO DAS METRÓPOLES. Sistema Metropolitano de Informaçōes Geográficas e Sociais para o Planejamento e Pesquisa: Geometropoles - Regiāo Metropolitana de Fortaleza. Rio de Janeiro: Observatório das Metrópoles, 2010.

OLIVEIRA, F.; BIASOTTO, R. O Acesso à terra urbanizada nos planos diretores brasileiros. In: SANTOS JUNIOR, O. A.; MONTANDON, D. T. (Org.). Os planos diretores municipais pós-estatuto da cidade: balanço crítico e perspectivas. Rio de Janeiro: Letra Capital; Observatório das Metrópoles; IPPUR/UFRJ, 2011.

PEQUENO, L. R. B. (Org.) Como anda Fortaleza. Rio de Janeiro: Letra Capital; Observatório das Metrópoles, 2009.

PROCURA por vazios estruturados. O Povo, Fortaleza, 8 nov. 2009, n.p.

RIBEIRO, L. C. Q.; LAGO, L. C. Reestruturação nas grandes cidades brasileiras: o modelo centro/periferia em questáo. Rio de Janeiro: IPPUR/UFRJ, 1994.

ROLNIK, R.; NAKANO, K. As armadilhas do pacote habitacional. Le Monde Diplomatique Brasil, 5 mar. 2009. Disponível em: <http://www.diplomatique.org.br/artigo. php?id=461>. Acesso em: 22 abr. 2015.

A B S T R A C T: Brazilian growing urban informality has been described as a by-product of both, the concentration of private real estate market on high-income strata, and the insufficient social housing public policies. Nevertheless, since mid 2000s the country witnessed a significant rise in investments targeting low-income housing provision. In order to contribute to a greater understanding of the socio-spatial effects of such change, this article questions to what extent it favored the access to the city for the low-income population in the Metropolitan Region of Fortaleza. It uses both quantitative (GIS, and secondary databank) and qualitative (Semi-structured interviews) methods to suggest the existence of a detachment between housing investments and urban policies inclusionary guidelines. If, on the one hand, it was possible to identify measures that could help to control rise in informality, such as the increase in formal housing provision for low and middle-income strata, on the other hand, the avoidance of measures to limit land speculative practices obstructs the possibility of socio-spatial inclusion through formal real estate market.

K E Y W O R D S : housing provision; urban inclusionary policies; urban informality; inclusionary zoning; Minha Casa, Minha Vida; Fortaleza. 